J. Dairy Sci. 96:1485-1498

http://dx.doi.org/10.3168/jds.2011-5250

(C) American Dairy Science Association ${ }^{\circledR}, 2013$.

\title{
Factors associated with fertility outcomes in cows treated with protocols to synchronize estrus and ovulation in seasonal-calving, pasture-based dairy production systems
}

\author{
M. M. Herlihy, ${ }^{\star} †$ M. A. Crowe,†‡ D. P. Berry, ${ }^{*}$ M. G. Diskin, $\S$ and S. T. Butler*1 \\ *Teagasc, Animal and Grassland Research and Innovation Centre, Moorepark, Fermoy, Co. Cork, Ireland \\ tUCD School of Veterinary Medicine, and \\ ‡UCD Conway Institute of Biomolecular and Biomedical Research, University College Dublin, Belfield, Dublin 4, Ireland \\ $\S$ Teagasc, Animal and Grassland Research and Innovation Centre, Mellows Campus, Athenry, Co. Galway, Ireland
}

\section{ABSTRACT}

Logistic regression was used to identify factors associated with fertility outcomes in cows treated with protocols to synchronize estrus and ovulation. Lactating dairy cows $(\mathrm{n}=1,538)$ were enrolled in a completely randomized block design study to evaluate synchronization treatments. Within each herd $(\mathrm{n}=8)$, cows were divided into 3 calving groups: early $[\geq 42 \mathrm{~d}$ in milk (DIM) at mating start date (MSD); $\mathrm{n}=1,244]$, mid (21 to 41 DIM at MSD; $\mathrm{n}=179$ ), and late (0 to 20 DIM at MSD; $\mathrm{n}=115$ ), based on DIM at MSD. Cows in the early-, mid-, and late-calving groups were synchronized to facilitate estrus or timed artificial insemination (TAI) at MSD (planned breeding 1; PB1), $21 \mathrm{~d}$ (PB2), and $42 \mathrm{~d}$ (PB3) after MSD, respectively. For each $\mathrm{PB}$, cows in the relevant calving group were stratified by parity and calving date and randomly assigned to (1) d -10 GnRH (10 $\mu \mathrm{g}$ i.m. of buserelin) and CIDR [controlled internal drug release insert, 1.38 $\mathrm{g}$ of progesterone (P4)]; d $-3 \mathrm{PGF}_{2 \alpha}(25 \mathrm{mg}$ i.m. of dinoprost); $\mathrm{d}-2$ CIDR out and AI at observed estrus (CIDR_OBS); (2) same as CIDR_OBS, but GnRH 36 $\mathrm{h}$ after CIDR out and TAI $18 \mathrm{~h}$ later (CIDR_TAI); (3) same as CIDR_TAI, but no CIDR (i.e., Ovsynch); or (4) untreated controls (CTRL). Use of a CIDR-based ovulation synchronization protocol (i.e., CIDR_TAI) increased synchronization rates in anovular cows. Both CIDR_OBS and CIDR_TAI animals without a corpus luteum (CL) had increased likelihood of conception at first service compared with Ovsynch animals without a CL. Animals with low body condition score (BCS) treated with CIDR_OBS had an increased likelihood of conceiving at first service compared with low-BCS animals treated with CIDR_TAI, Ovsynch, or CTRL. Animals $<60 \mathrm{~d}$ in milk (DIM) treated with

Received December 9, 2011.

Accepted November 9, 2012.

${ }^{1}$ Corresponding author: Stephen.Butler@teagasc.ie
CIDR_OBS and CIDR_TAI had increased likelihood of conceiving at first service compared with animals treated with Ovsynch. Treatment with CIDR_TAI increased synchronization rate in cows categorized as low BCS, anovulatory, and <60 DIM compared with both CIDR_OBS and Ovsynch, and increased submission rate compared with CIDR_OBS. Conception rate in cows within these categories, however, was greatest for CIDR_OBS, resulting in minimal differences in actual pregnancy rates between CIDR_OBS and CIDR_TAI treatments, both of which were superior to Ovsynch. Treatment differences in the response variables investigated were minimal in cows categorized as medium or high BCS, ovulatory, and >60 DIM, indicating that CIDR-based protocols could be targeted at particular cows, and all other cows could be synchronized using Ovsynch.

Key words: estrous synchronization, Ovsynch, dairy cow, seasonal calving

\section{INTRODUCTION}

The success of a seasonal-calving, pasture-based milk production system is largely dependent on achieving a compact calving pattern to coincide with the start of the grass growing season, thus matching the seasonal supply of pasture to the herd intake demand (Dillon et al., 1995). A key measure of reproductive performance in seasonal-calving dairy herds is the 42-d pregnancy rate (McDougall, 2006), which is defined as the percentage of the herd confirmed pregnant to inseminations performed during the first $42 \mathrm{~d}$ following the mating start date (MSD). The 42-d pregnancy rate of a herd is primarily influenced by the 21-d submission rate and the conception rate at first service.

Synchronization can play a critical part in maintaining a herd's seasonally concentrated calving pattern. Programs for estrous cycle control facilitate the breeding of large numbers of animals over a short time using either estrus detection or $\mathrm{AI}$ at a predetermined time 
(timed AI; TAI) without the requirement for detection of estrus (Macmillan, 2010). Several cow factors affect synchronization and conception rates after application of TAI protocols in lactating dairy cows. These include stage of the estrous cycle at the onset of TAI protocols, DIM, BCS at calving and AI, parity, and presence or absence of a corpus luteum (CL) at the onset of synchronization (Tenhagen et al., 2004; Bello et al., 2006; Galvão and Santos, 2010).

Greater DIM results in increased likelihood of conception in cows early postpartum following insemination based on observed estrus (Butler and Smith, 1989) or after TAI (Tenhagen et al., 2003). Greater conception rates in primiparous cows compared with multiparous cows following Ovsynch have been reported (Tenhagen et al., 2001, 2004). Lopez et al. (2004) reported that increased milk production $(\geq 39.5 \mathrm{~kg} / \mathrm{d})$ decreased the duration of estrus in nonsynchronized lactating dairy cows. When TAI protocols are used, however, animals are submitted for AI without reliance on behavioral estrus detection. Thus, use of TAI protocols facilitates $100 \%$ submission rates in all cows, regardless of level of milk production. Cows in low BCS at parturition or that experienced excessive BCS loss early postpartum are less likely to ovulate before the planned start of mating, and thus have reduced submission rates to AI, reduced conception rates, and increased likelihood of pregnancy loss (Roche et al., 2009). Recent studies have indicated that BCS is also an important factor affecting conception rates following TAI protocols (Moreira et al., 2000; Galvão and Santos, 2010).

The single most important ovarian factor influencing success rates achieved with TAI protocols is the cyclicity status of the animal. A recent study conducted in seasonal-calving dairy herds in New Zealand reported greater first-service conception rates for anestrous cows that had a CL present at protocol enrollment compared with cows without a CL (43.1 vs. $33.4 \%$, respectively; McDougall, 2010a). Gümen et al. (2003) reported reduced fertility performance following Ovsynch in cows identified as anovular at the onset of synchronization compared with ovular cows, possibly due to increased incidence of premature luteal regression in the former. Improved pregnancy outcomes were documented when an intravaginal progesterone (P4) insert was included during Ovsynch for anovular cows, where GnRH was used to synchronize the growth of a new follicular wave at protocol initiation and to synchronize ovulation (Stevenson et al., 2008; Chebel et al., 2010; McDougall, 2010a). Following P4 withdrawal at the end of a treatment period, a rapid decrease in circulating concentrations of $\mathrm{P} 4$ promotes a synchronous estrus within the herd, allowing for AI of large numbers of animals (Macmillan and Peterson, 1993).
Herlihy et al. (2011) reported that the use of TAI protocols in seasonal-calving cows on pasture-based dairy production systems resulted in both shorter intervals from calving to first service and shorter intervals from MSD to conception. The objective of this study was to further analyze this data set to identify factors associated with fertility outcomes in cows treated with protocols to synchronize estrus and ovulation. The results will aid identification of the optimum synchronization protocol for cows in different physiological conditions.

\section{MATERIALS AND METHODS}

\section{Experimental Design}

In this study, 1,538 lactating dairy cows in 8 Irish commercial spring-calving dairy herds were used in a completely randomized block experimental design to evaluate synchronization protocols between April and June 2008, as previously described (Herlihy et al., 2011). Briefly, within each herd, cows were divided into 3 groups: early, mid, and late calving based on DIM at the farm MSD. Early-calving cows $(\mathrm{n}=1,244)$ were $\geq 42$ DIM at MSD, mid-calving cows $(n=179)$ were 21 to 41 DIM at MSD, and late-calving cows $(\mathrm{n}=115)$ were 0 to 20 DIM at MSD. Synchronization protocols commenced $10 \mathrm{~d}$ before MSD for the early-calving cows, facilitating estrus or TAI at MSD [planned breeding (PB)1] as illustrated in Figure 1 (upper panel). All early-calving cows were $\geq 42$ DIM at AI (range 42 to 105). Synchronization treatments commenced on d 11 and 32 after MSD for the mid- and late-calving cows, respectively. The treatments facilitated estrus or TAI 21 $\mathrm{d}$ after MSD (PB2) and $42 \mathrm{~d}$ after MSD (PB3) for the mid- and late-calving cows, respectively. All mid- and late-calving cows were between 42 and 62 DIM at AI. Thus, the experimental treatments were imposed on all cows that had calved up to and including MSD. All experimental procedures involving animals were licensed by the Department of Health and Children, Ireland, in accordance with the Cruelty to Animals Act (Ireland 1876) and European Community Directive 86/609/EC, and were sanctioned by the University College Dublin Animal Research Ethics Committee.

\section{Synchronization Treatments and AI}

Within each calving group, cows were stratified by parity and DIM and randomly assigned to 1 of the 4 treatments illustrated in Figure 1 (lower panel). One protocol was an estrous synchronization protocol: CIDR_OBS: d -10 GnRH [GnRH1; $10 \mu \mathrm{g}$ of buserelin (2.5 mL of Receptal), i.m.] and controlled internal drug release insert [CIDR; $1.38 \mathrm{~g}$ of progesterone $(\mathbf{P 4})$ ]; 

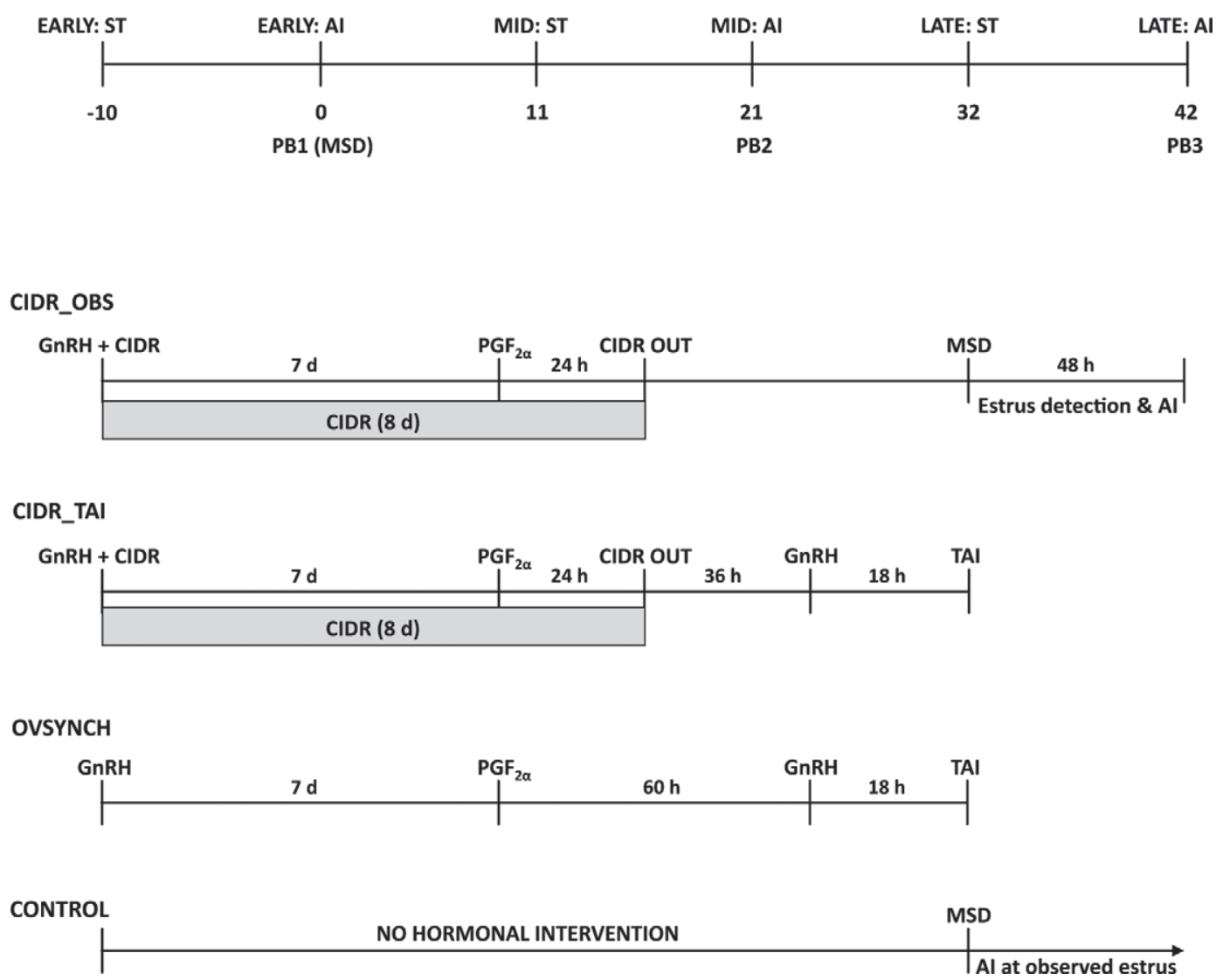

Figure 1. Schematic diagram of experimental timeline used to evaluate synchronization treatments (ST; upper panel) and treatment protocols to synchronize estrus and ovulation (lower panel). Early-calving cows were $\geq 42$ DIM at mating start date (MSD), mid-calving cows were 21 to 41 DIM at MSD, and late-calving cows were 0 to 20 DIM at MSD. PB = planned breeding 1 (MSD), 2, and 3. For each seasonal-calving farm in the study $(\mathrm{n}=8)$, breeding started on a fixed calendar date (MSD). In this study, PB1 coincided with the MSD for each farm, PB2 occurred $21 \mathrm{~d}$ after PB1, and PB3 occurred $42 \mathrm{~d}$ after PB1 or $21 \mathrm{~d}$ after PB2. Treatment protocols for synchronization were initiated at a random stage of the estrous cycle and applied to lactating dairy cows before first service. CIDR $=$ controlled internal drug release; OBS $=$ observed estrus; $\mathrm{TAI}=$ timed AI.

$\mathrm{d}-3 \mathrm{PGF}_{2 \alpha}$ [25 $\mathrm{mg}$ of dinoprost (5 $\mathrm{mL}$ of Lutalyse), i.m.]; d -2 CIDR out; and AI at observed estrus. Two protocols were ovulation synchronization protocols: (1) CIDR_TAI was the same as CIDR_OBS, but with GnRH (GnRH2) $36 \mathrm{~h}$ after CIDR out and TAI $18 \mathrm{~h}$ later; (2) Ovsynch was the same as CIDR_TAI, but with no CIDR. All synchronization protocols were initiated at a random stage of the estrous cycle. Cows assigned to the control (CTRL) treatment $(\mathrm{n}=387)$ received no hormonal intervention. The i.m. GnRH agonist injections contained $10 \mu \mathrm{g}$ of buserelin (Receptal, Intervet Ireland Ltd., Dublin, Ireland). The CIDR device used contained $1.38 \mathrm{~g}$ of $\mathrm{P} 4$ (Pfizer Ireland, Dublin, Ireland). The i.m. $\mathrm{PGF}_{2 \alpha}$ contained $25 \mathrm{mg}$ of dinoprost tromethamine (Lutalyse; Pfizer Ireland). All hormonal treatments were administered by research staff from Teagasc Moorepark (Fermoy, Co. Cork, Ireland). Cows assigned to CTRL and CIDR_OBS were inseminated according to the a.m./p.m. rule (Nebel et al., 1994), following detection of estrus with the aid of tail paint. All cows on the CIDR_TAI and Ovsynch protocols received TAI $18 \mathrm{~h}$ after $\mathrm{GnRH} 2$, and $\mathrm{GnRH} 2$ was administered $60 \mathrm{~h}$ after $\mathrm{PGF}_{2 \alpha}$ injection.

\section{Transrectal Ultrasonography}

The reproductive tracts of all cows were examined immediately before initiation of synchronization treatments by linear-array ultrasonography using a $5.0-\mathrm{MHz}$ transrectal transducer (Aloka SSD-500; Aloka Ltd., Tokyo, Japan). Corpora lutea, large follicles (LF, $\geq 10$ $\mathrm{mm}$ ), and medium follicles (5 to $9 \mathrm{~mm}$ ) were counted and recorded for each ovary; the size of ovarian structures was not determined (small follicles $<5 \mathrm{~mm}$ were not counted in this study). Cows were assigned an ultrasound reproductive tract score describing the volume and echogenicity of fluid contained within the uterus (Mee et al., 2009). Cows classified as endome- 
tritic were removed from the study. To determine rates of conception and late embryo loss, all cows on synchronization treatments were initially examined at 30 to $32 \mathrm{~d}$ and again at 56 to $58 \mathrm{~d}$ post-AI by linear-array ultrasonography using a $5.0-\mathrm{MHz}$ transrectal transducer. For CTRL cows, the mean (SD) days post-AI at the corresponding scans were $41.2(7.8)$ and 64.2 (6.2), respectively. On each day of pregnancy diagnosis, visualization of a fluid-filled uterine horn and the presence of a conceptus were used as positive indicators of pregnancy. The CTRL animals in the present study were inseminated based on observed estrus. For logistical reasons, it was not possible to carry out the pregnancy diagnosis for CTRL cows at the same days post-AI as was done for cows on synchrony treatments. Consequently, both the conception rate to $\mathrm{AI}$ and the embryo loss rate for CTRL animals in the present study may have been slightly underestimated relative to those of the synchrony treatments.

\section{Blood Collection and Progesterone RIA}

Blood was collected in lithium heparin Vacutainer tubes (Becton Dickinson and Co., Plymouth, UK) by puncture of coccygeal vessels on the day of PB1 (early cows), PB2 (mid cows), and PB3 (late cows) and again $11 \mathrm{~d}$ after PB1, PB2, and PB3. Blood samples were immediately placed in ice and later centrifuged at 2,000 $\times g$ for $15 \mathrm{~min}$ at $5^{\circ} \mathrm{C}$; the plasma was harvested and stored at $-20^{\circ} \mathrm{C}$ until later analysis. Concentrations of $\mathrm{P} 4$ in plasma were determined using a commercially available solid-phase RIA (Coat-A-Count Progesterone; Diagnostic Products Corp., Los Angeles, CA). The sensitivity of the assay was $0.08 \mathrm{ng} / \mathrm{mL}$. The inter-assay CV were $9.35 \%$ (high), $6.50 \%$ (medium), and $17.8 \%$ (low), respectively. The intra-assay CV were 8.53, 8.45, and $26.0 \%$, respectively.

\section{Synchronization Rate}

Cows were categorized according to plasma $\mathrm{P} 4$ at $\mathrm{d} 0$ (presumptive estrus) and d 11 after insemination (high, $\mathbf{H}, \geq 1 \mathrm{ng} / \mathrm{mL}$; low, $\mathbf{L},<1 \mathrm{ng} / \mathrm{mL}$ ). Cows were grouped into $\mathrm{P} 4$ classes that resulted in 4 possible $\mathrm{P} 4$ class permutations for synchronized cows: HH, LL, HL, and LH. Only cows with L plasma $\mathrm{P} 4$ on $\mathrm{d} 0$ and $\mathrm{H}$ plasma $\mathrm{P} 4$ on d 11 (i.e., LH) were considered synchronized.

\section{Reproductive Measurements}

The following reproductive measurements were calculated and analyzed: 21-d submission relative to PB1, PB2, PB3 (binary); conception at first service (confirmed pregnant by ultrasonography at 30 to $32 \mathrm{~d}$ after first AI; binary); pregnancy at first service (submitted for insemination in the first $21 \mathrm{~d}$ after PB and confirmed pregnant by ultrasonography at 30 to $32 \mathrm{~d}$ after first AI (binary); and late embryonic loss after first service [loss of a viable pregnancy between pregnancy diagnosis 1 (d 30 to 32 post-AI) and pregnancy diagnosis 2 (d 56 to 58 post-AI; binary)]. For animals treated with CIDR_TAI and Ovsynch, only animals that conceived or failed to conceive on the day of the synchronized $\mathrm{PB}$ were included in the analysis of conception at first service. For animals treated with CIDR_OBS, only animals that conceived or failed to conceive within 5 $\mathrm{d}$ of the synchronized PB were included in the analysis of conception at first service. For CTRL animals, only animals that conceived or failed to conceive within 21 $\mathrm{d}$ of the synchronized PB period were included in the analysis of conception at first service.

\section{Milk Production and BCS}

Milk production data consisting of test-day milk records for each individual cow were extracted from the Irish Cattle Breeding Federation database. Cows were, on average, milk recorded every 6 wk and 6 times per lactation. Cubic splines with 6 knot points at 20,70, $120,170,220$, and 270 DIM were fitted through individual test-day records of milk, fat, and protein yields with a covariance structure fitted among knot points. Milk and fat yields on the date of insemination were estimated from the fitted spline for each cow separately, and $4 \% \mathrm{FCM}$ on the day of AI was calculated as follows: $4 \% \mathrm{FCM}=(0.4 \times \mathrm{kg}$ of milk/d $)+(15 \times \mathrm{kg}$ of fat/d) (Gaines and Davidson, 1923). Body condition score was recorded at the time of insemination on a 1 to 5 scale $(1=$ emaciated, $5=$ extremely fat $)$ with increments of 0.25 as outlined by Edmonson et al. (1989); BCS was measured by 1 of 4 trained research staff from Teagasc Moorepark.

\section{Statistical Analyses}

Explanatory independent variables considered for inclusion in all models included treatment $(\mathrm{n}=4)$, farm $(\mathrm{n}=8)$, parity of the cow $(1,2, \geq 3)$, DIM $(<60$ DIM, $\geq 60$ and $\leq 80$ DIM, or $>80$ DIM), breed fraction of the cow as continuous variables (Holstein-Friesian, Jersey, Norwegian Red, and "other"), and heterosis and recombination loss coefficients of the cow as continuous variables. Breed fraction, recorded in increments of $1 / 32$, was fitted as a continuous variable to account for differences in the proportion of each breed (Holstein Friesian, Jersey, Norwegian Red, and "other") in an animal; each breed was fitted as a separate covariate. The associations between LF status, CL status, parity, 
BCS, DIM at AI or DIM at the synchronized PB, P4 on d 11 after AI (conception at first service and late embryo loss after first service only), 4\% FCM at AI and (1) synchronization rate, (2) 21-d submission rate after $\mathrm{PB}$, and (3) conception at first service for different synchronization treatments were determined by logistic regression using the GENMOD procedure of SAS (SAS Institute, 2006); 2-way interactions between the effects listed and synchronization treatment were also evaluated. A logit link function was used and a binomial distribution of the data was assumed. The logit of the probability of a positive outcome was modelled.

Model solutions were converted back to predicted probabilities $(P)$ as:

$$
P=\left[1+\mathrm{e}^{-(\alpha+\beta \mathrm{x})}\right]^{-1},
$$

where $\alpha$ is the predicted intercept of the model, $\boldsymbol{\beta}$ is the predicted regression coefficient(s), and $\mathbf{X}$ is the design matrix for the fixed effects in the model. The intercept represented the average farm and was representative of the average parity structure and calving date structure in the data except when the predicted probabilities of either parity or calving date were required. Predicted probabilities may be interpreted as least squares means for the variable of interest estimated using linear models. Differences between treatments were declared significant when $P \leq 0.05$, and a tendency toward significance was assumed when $0.05<P \leq 0.10$.

Odds ratios $(\mathbf{O R})$ were calculated as the exponent of the model solutions. The CTRL synchronization treatment was used as the reference group for conception at first service and 21-d submission rate after PB. For synchronization rate, CTRL animals were removed from the analysis and the Ovsynch synchronization treatment was used as the reference group.

When investigating the interaction between synchronization treatment and DIM, BCS, P4, and 4\% FCM at AI, all variables were separately tested either as continuous variables or as classification variables. Nonlinear associations between continuous variables (i.e., DIM, BCS, P4, and 4\% FCM at AI fitted as linear and quadratic terms) and synchronization rate, 21-d submission after $\mathrm{PB}$, and conception at first service were also tested. For continuous variables, the results presented in the figures are based on modeling the variable as a continuous variable, and the results presented in the text are based on modeling the variable as a classification variable. When significant, preplanned contrasts based on modeling the variable as a classification variable are indicated in the figures.

Stage of lactation was described by the following variables: DIM at AI (used in the analysis of conception at first service) or DIM at synchronized PB (used in the analysis of synchronization rate and 21-d submission rate after $\mathrm{PB}$ ). Cows were classified according to stage of lactation as $<60$ DIM, $\geq 60$ and $\leq 80$ DIM, or $>80$ DIM. Cows were also separately classified according to (a) BCS at the time of insemination as $\leq 2.50$ (low), $\geq 2.75$ and $\leq 3.00$ (medium), or $\geq 3.25$ (high) (Buckley et al., 2003); (b) circulating concentrations of P4 on d 11 after $\mathrm{AI}$ as $\geq 1.00$ and $<3.50 \mathrm{ng} / \mathrm{mL}$ (low), $\geq 3.50$ and $<5.00 \mathrm{ng} / \mathrm{mL}$ (medium-low), $\geq 5.00$ and $<7.00 \mathrm{ng} /$ $\mathrm{mL}$ (medium-high), and $\geq 7.00 \mathrm{ng} / \mathrm{mL}$ (high); animals with $\mathrm{P} 4<1.00 \mathrm{ng} / \mathrm{mL}$ on $\mathrm{d} 11$ after AI were removed from the data set; and (c) $4 \% \mathrm{FCM}$ on the day of AI as $\geq 10.00$ and $<20.50 \mathrm{~kg} / \mathrm{d}$ (low), $\geq 20.50$ and $<24.50$ $\mathrm{kg} / \mathrm{d}$ (medium-low), $\geq 24.50$ and $<29.00 \mathrm{~kg} / \mathrm{d}$ (mediumhigh), and $\geq 29.00 \mathrm{~kg} / \mathrm{d}$ (high). Animals with $4 \% \mathrm{FCM}$ $<10.00 \mathrm{~kg} / \mathrm{d}$ on the day of AI were removed from the data set.

\section{RESULTS}

By definition, both TAI protocols (i.e., CIDR_TAI and Ovsynch) resulted in 21-d submission rates after PB of 1.00 (i.e., 100\%). Hence, TAI protocols were not included in the analysis of 21-d submission rate after PB. No evidence was found of a nonlinear association between the continuous variables investigated (i.e., $\mathrm{BCS}$ at $\mathrm{AI}, \mathrm{DIM}$ at the synchronized PB/AI, 4\% FCM at $\mathrm{AI}$, and $\mathrm{P} 4$ on $\mathrm{d} 11$ after $\mathrm{AI}$ ) and either the logit of synchronization rate, 21-d submission rate after $\mathrm{PB}$, conception rate at first service, or late embryo loss after first service (all $P>0.10$ ). Across all analyses, the associations between response and explanatory variables were generally similar regardless of whether the factor under investigation was included in the statistical model as either a class or a continuous variable. Therefore, all results presented in the text hereafter are from the analysis that included each explanatory factor in the model as a class effect.

The associations between each factor and synchronization rate, 21-d submission rate after $\mathrm{PB}$, conception rate at first service, and pregnancy rate at first service are summarized in Table 1 . The intercepts of the multiple regression models for synchronization rate, 21-d submission rate after planned breeding, conception rate at first service, and pregnancy rate at first service when each explanatory factor was included in the model as a classification variable are summarized in Table 2 . The intercept of the multiple regression model for late embryo loss after first service was $-2.51(\mathrm{SE}=0.83)$.

\section{Large Follicle Status}

The association between synchronization treatment and either synchronization rate or conception rate at 
Table 1. Predicted probability (PP; SE in parentheses) for the association between each explanatory factor and synchronization rate, 21-d submission after planned breeding (PB), conception at first service, and pregnancy at first service

\begin{tabular}{|c|c|c|c|c|c|c|c|c|}
\hline \multirow[b]{2}{*}{ Factor $^{1}$} & \multicolumn{2}{|c|}{$\begin{array}{l}\text { Synchronization } \\
\text { rate }\end{array}$} & \multicolumn{2}{|c|}{$\begin{array}{c}\text { 21-d submission rate } \\
\text { after } \mathrm{PB}\end{array}$} & \multicolumn{2}{|c|}{$\begin{array}{l}\text { Conception rate at } \\
\text { first service }\end{array}$} & \multicolumn{2}{|c|}{$\begin{array}{l}\text { Pregnancy } \\
\text { rate at first service }\end{array}$} \\
\hline & PP (SE) & $P$-value & $\mathrm{PP}(\mathrm{SE})$ & $P$-value & PP (SE) & $P$-value & $\mathrm{PP}(\mathrm{SE})$ & $P$-value \\
\hline $\begin{array}{l}\text { LF status } \\
\text { No LF present } \\
\text { LF present }\end{array}$ & $\begin{array}{l}0.85(0.02)^{\mathrm{a}} \\
0.89(0.01)^{\mathrm{b}}\end{array}$ & 0.05 & $\begin{array}{l}0.90(0.02)^{\mathrm{a}} \\
0.85(0.02)^{\mathrm{b}}\end{array}$ & 0.05 & $\begin{array}{l}0.41(0.03)^{\mathrm{a}} \\
0.48(0.02)^{\mathrm{b}}\end{array}$ & 0.03 & $\begin{array}{l}0.40(0.03)^{\mathrm{a}} \\
0.48(0.02)^{\mathrm{b}}\end{array}$ & 0.02 \\
\hline $\begin{array}{l}\text { BCS at AI } \\
\text { Low } \\
\text { Medium } \\
\text { High }\end{array}$ & $\begin{array}{l}0.83(0.02)^{\mathrm{a}} \\
0.90(0.01)^{\mathrm{b}} \\
0.90(0.03)^{\mathrm{b}}\end{array}$ & 0.01 & $\begin{array}{l}0.79(0.03)^{\mathrm{a}} \\
0.88(0.02)^{\mathrm{b}} \\
0.88(0.03)^{\mathrm{b}}\end{array}$ & 0.02 & $\begin{array}{l}0.47(0.02)^{\mathrm{a}} \\
0.55(0.02)^{\mathrm{b}} \\
0.60(0.04)^{\mathrm{b}}\end{array}$ & 0.008 & $\begin{array}{l}0.43(0.02)^{\mathrm{a}} \\
0.50(0.02)^{\mathrm{b}} \\
0.54(0.04)^{\mathrm{b}}\end{array}$ & 0.05 \\
\hline $\begin{array}{l}\text { Parity } \\
1 \\
2 \\
\geq 3\end{array}$ & $\begin{array}{l}0.83(0.02)^{\mathrm{a}} \\
0.84(0.02)^{\mathrm{a}} \\
0.91(0.01)^{\mathrm{b}}\end{array}$ & 0.002 & $\begin{array}{l}0.84(0.03) \\
0.85(0.03) \\
0.87(0.02)\end{array}$ & 0.50 & $\begin{array}{l}0.56(0.03)^{\mathrm{a}} \\
0.58(0.03)^{\mathrm{a}} \\
0.50(0.02)^{\mathrm{b}}\end{array}$ & 0.04 & $\begin{array}{l}0.51(0.03)^{\mathrm{x}} \\
0.52(0.03)^{\mathrm{x}} \\
0.45(0.02)^{\mathrm{y}}\end{array}$ & 0.10 \\
\hline $\begin{array}{l}\text { 4\% FCM at AI } \\
\text { Low } \\
\text { Medium-low } \\
\text { Medium-high } \\
\text { High }\end{array}$ & $\begin{array}{l}0.86(0.02) \\
0.90(0.02) \\
0.92(0.02) \\
0.89(0.02)\end{array}$ & 0.30 & $\begin{array}{l}0.85(0.03) \\
0.87(0.03) \\
0.88(0.03) \\
0.84(0.03)\end{array}$ & 0.80 & $\begin{array}{l}0.54(0.03) \\
0.57(0.03) \\
0.49(0.03) \\
0.50(0.03)\end{array}$ & 0.40 & $\begin{array}{l}0.50(0.03) \\
0.52(0.03) \\
0.43(0.03) \\
0.44(0.03)\end{array}$ & 0.30 \\
\hline $\begin{array}{l}\text { P4 d11 after AI } \\
\text { Low } \\
\text { Medium-low } \\
\text { Medium-high } \\
\text { High }\end{array}$ & & & & & $\begin{array}{l}0.41(0.04)^{\mathrm{a}} \\
0.52(0.03)^{\mathrm{b}} \\
0.53(0.03)^{\mathrm{b}} \\
0.56(0.04)^{\mathrm{b}}\end{array}$ & 0.04 & & \\
\hline
\end{tabular}

\footnotetext{
$\overline{\mathrm{a}, \mathrm{b}}$ Predicted probabilities within a response variable for a particular explanatory factor with different superscripts differ $(P<0.05)$.

${ }^{\mathrm{x}, \mathrm{y}}$ Predicted probabilities within a response variable for a particular explanatory factor with different superscripts tend to differ $(P \leq 0.10)$

${ }^{1} \mathrm{LF}=$ large follicle; $\mathrm{CL}=$ corpus luteum; DIM at PB/AI = DIM at synchronized planned breeding/AI; P4 = progesterone.
}

first service did not differ by LF status $(P=0.4$ and $P$ $=0.9$, respectively), but the association between synchronization treatment and 21-d submission rate after PB did differ by LF status at protocol initiation $(P$ $=0.05 ;$ Figure 2$)$. The interaction arose because $21-\mathrm{d}$ submission after $\mathrm{PB}$ was 7.0 percentage units greater for CIDR_OBS animals without a LF present at the onset of synchronization compared with animals with a LF present, whereas the 21-d submission rate after PB was similar for CTRL treatment animals with or without a LF present when synchronization protocols were initiated.

\section{Corpus Luteum Status}

The association between synchronization treatment and synchronization rate differed by CL status at pro- tocol initiation $(P=0.03)$, but no interaction between synchronization treatment and CL status was observed for 21-d submission rate after $\mathrm{PB}$ or conception rate at first service $(P=0.9$ and $P=0.5$, respectively; Figure $2)$. The interaction arose because synchronization rates were 18.0 and 16.0 percentage units greater for CIDR OBS and Ovsynch animals with a CL present at the onset of synchronization, respectively, compared with animals without a CL present; synchronization rates were similar for CIDR_TAI animals with or without a CL present at the onset of synchronization. Preplanned contrasts used to compare treatment effects within CL status indicated that conception rate was 15.0 percentage units greater in Ovsynch animals with a CL compared with Ovsynch animals without a CL present at the onset of synchronization. For animals with no $\mathrm{CL}$ at the time of treatment initiation, inseminations 
Table 2. Intercept ${ }^{1}$ (SE in parentheses) of the logit of the probability of a positive outcome from the multiple regression models for synchronization rate, 21-d submission rate after planned breeding (PB), conception rate at first service, and pregnancy rate at first service

\begin{tabular}{lcccr}
\hline Factor $^{2}$ & $\begin{array}{c}\text { Synchronization } \\
\text { rate }\end{array}$ & $\begin{array}{c}\text { 21-d submission } \\
\text { after PB }\end{array}$ & $\begin{array}{c}\text { Conception at first } \\
\text { service }\end{array}$ & $\begin{array}{c}\text { Pregnancy at first } \\
\text { service }\end{array}$ \\
\hline LF status & $2.13(0.54)^{\mathrm{a}}$ & $1.71(0.56)^{\mathrm{a}}$ & $-0.08(0.27)$ & $-0.09(0.27)$ \\
CL status & $2.65(0.58)^{\mathrm{a}}$ & $1.98(0.56)^{\mathrm{a}}$ & $0.24(0.22)^{\mathrm{b}}$ & $0.02(0.22)$ \\
BCS at AI & $2.23(0.62)^{\mathrm{a}}$ & $1.99(0.61)^{\mathrm{a}}$ & $0.41(0.26)^{\mathrm{b}}$ & $0.14(0.26)^{\mathrm{b}}$ \\
DIM at PB/AI & $2.66(0.53)^{\mathrm{a}}$ & $2.89(0.55)^{\mathrm{a}}$ & $0.34(0.22)^{\mathrm{b}}$ & $0.25(0.22)$ \\
Parity & $2.33(0.53)^{\mathrm{a}}$ & $1.93(0.55)^{\mathrm{a}}$ & $-0.001(0.22)^{\mathrm{b}}$ & $-0.19(0.22)$ \\
$4 \%$ FCM at AI & $2.12(0.60)^{\mathrm{a}}$ & $1.67(0.80)^{\mathrm{a}}$ & $0.001(0.26)^{\mathrm{c}}$ & $-0.23(0.26)$ \\
P4 d 11 after AI & & & $0.25(0.32)$ & \\
\hline
\end{tabular}

$\overline{\mathrm{a}-\mathrm{c} I n t e r c e p t s}$ with superscripts differ from zero $(\mathrm{a}=P \leq 0.001 ; \mathrm{b}=0.001<P \leq 0.05 ; \mathrm{c}=0.05<P \leq 0.10)$.

${ }^{1}$ The intercept represented the average farm and was representative of the average parity structure and calving date structure in the data except when the predicted probabilities of either parity or calving date were required. The average calving date and parity for animals in the study $(\mathrm{n}=1,538)$ was February 23,2008 , and 3 , respectively.

${ }^{2} \mathrm{LF}=$ large follicle; $\mathrm{CL}=$ corpus luteum; $\mathrm{DIM}$ at $\mathrm{PB} / \mathrm{AI}=\mathrm{DIM}$ at synchronized planned breeding $/ \mathrm{AI} ; \mathrm{P} 4=$ progesterone.

based on observed estrus (i.e., CIDR_OBS and CTRL) had an increased likelihood of conceiving at first service compared with animals treated using TAI protocols (i.e., CIDR_TAI and Ovsynch; OR $=1.49, P=0.03$ ).

\section{BCS}

The association between synchronization treatment and synchronization rate, 21-d submission rate after $\mathrm{PB}$, and conception rate at first service differed by BCS at AI $(P=0.04, P=0.01$, and $P=0.10$, respectively; Figure 3$)$. A greater predicted probability of anovulation was observed among low- and medium-BCS animals compared with high-BCS animals $(0.36,0.30$, and 0.21 for low, medium, and high BCS, respectively; all $P<0.05)$. Details of the association between synchronization treatment and BCS are indicated in Figure 3. The interaction between synchronization treatment and synchronization rate was due to the greater synchronization rates for CIDR_TAI compared with CIDR_OBS and Ovsynch animals in the low $(+11.0$ and +14.0 percentage units, respectively) and medium $(+7.0$ and +5.0 percentage units, respectively) BCS categories. In addition, Ovsynch cows in the high BCS category had synchronization rates 14.0 and 12.0 percentage units lower compared with CIDR_OBS and CIDR_TAI, respectively. The interaction between synchronization treatment and conception rate at first service was due to the greater conception rate for CIDR_OBS animals in the low BCS category when compared with CIDR_TAI $(+15.0$ percentage units), Ovsynch $(+18.0$ percentage units), and CTRL (+21.0 percentage units). Medium BCS category cows had greater conception rates when treated with CIDR_OBS (+12.0 percentage units) and CIDR_TAI (+10.0 percentage units) compared with Ovsynch. Cows in the high BCS category had greater conception rates when treated with CIDR_OBS $(+19.0$ percentage units $), \quad$ CIDR_TAI $\quad(+23.0$ percentage units), and CTRL (+31.0 percentage units) compared with Ovsynch.

\section{DIM at Synchronized Planned Breeding/DIM at AI}

The association between synchronization treatment and 21-d submission rate after PB differed by DIM at the synchronized PB $(P=0.006)$, but no interaction was observed between synchronization treatment and DIM at the synchronized PB for synchronization rate or between synchronization treatment and DIM at AI for conception rate at first service $(P=0.4$ and $P=$ 0.17 , respectively; Figure 4). Details of the association between synchronization treatment and DIM at the synchronized PB/AI are illustrated in Figure 4. The interaction between synchronization treatment and 21-d submission rate after $\mathrm{PB}$ was due to the 15.0 percentage unit greater 21-d submission rate for CIDR_OBS animals in the $<60$ DIM category compared with animals treated with CTRL. Preplanned contrasts used to compare treatment effects within DIM category indicated greater synchronization rates for CIDR_TAI compared with CIDR_OBS and Ovsynch animals in the $<60$ DIM $(+14.0$ and +12.0 percentage units, respectively) and the 60 to 80 DIM categories $(+4.0$ and +8.0 percentage units, respectively). In addition, conception rates were greater for CIDR_OBS $(+27.0$ percentage units), CIDR_TAI (+18.0 percentage units), and CTRL (+12.0 percentage units) animals in the $<60$ DIM category compared with Ovsynch.

\section{Parity}

The association between synchronization treatment and synchronization rate, 21-d submission rate after 

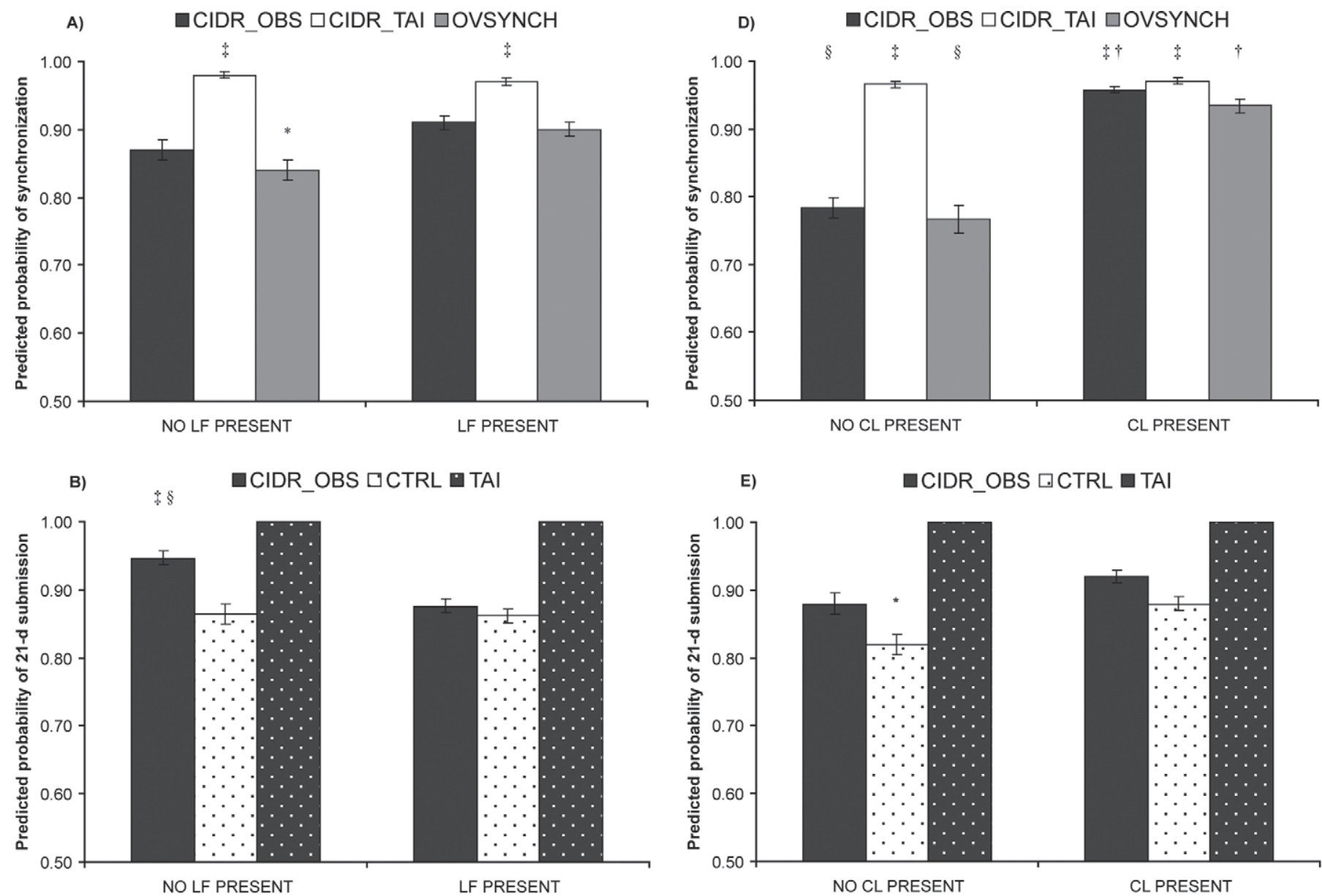

c) $\quad$ CIDR_OBS $\square$ CIDR_TAI $\square O V S Y N C H$

F) $\quad$ aCIDR_OBS $\square$ CIDR_TAI $\square O V S Y N C H \square C T R L$

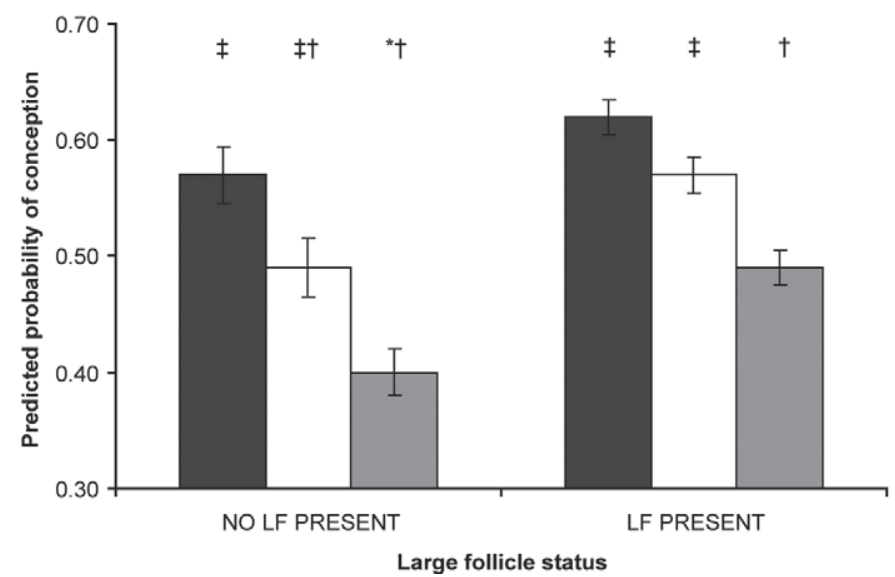

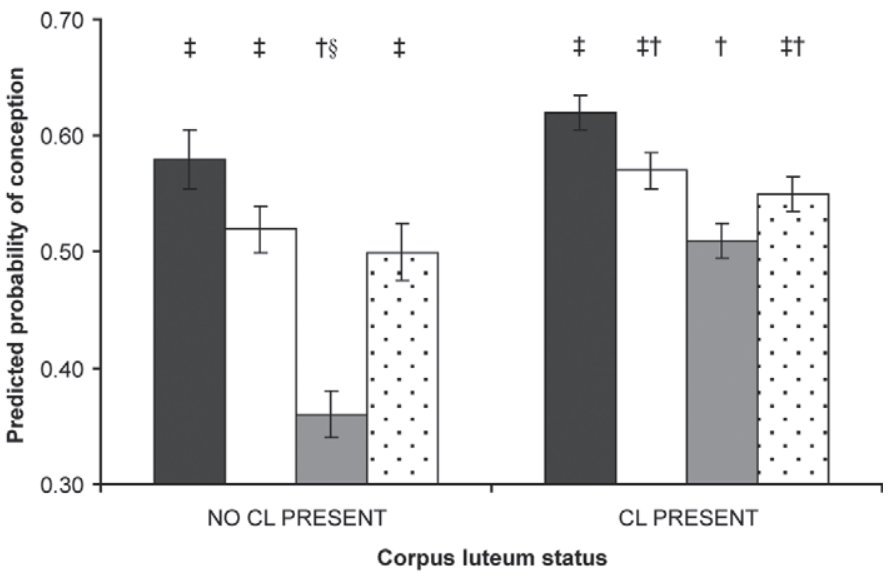

Figure 2. The association between large follicle (LF) and corpus luteum (CL) status at protocol initiation and synchronization rate (A and $\mathrm{D}$, respectively), 21-d submission rate after planned breeding (B and E, respectively), and conception rate at first service (C and F, respectively) for different synchronization treatments. $\dagger \dagger$ Treatments differ within a particular CL or LF status $(P \leq 0.05)$; $\S$ within-treatment differences between CL or LF status $(P \leq 0.05)$; *within-treatment tendency toward differences between LF or CL status $(P \leq 0.10)$.

$\mathrm{PB}$, and conception rate at first service did not differ $(P>0.3)$ by parity (Figure 5$)$. A greater probability of anovulation was observed among primiparous animals compared with multiparous animals $(0.42,0.32$, and 0.30 for first, second, and third and greater parity, respectively; all $P<0.05$ ). 

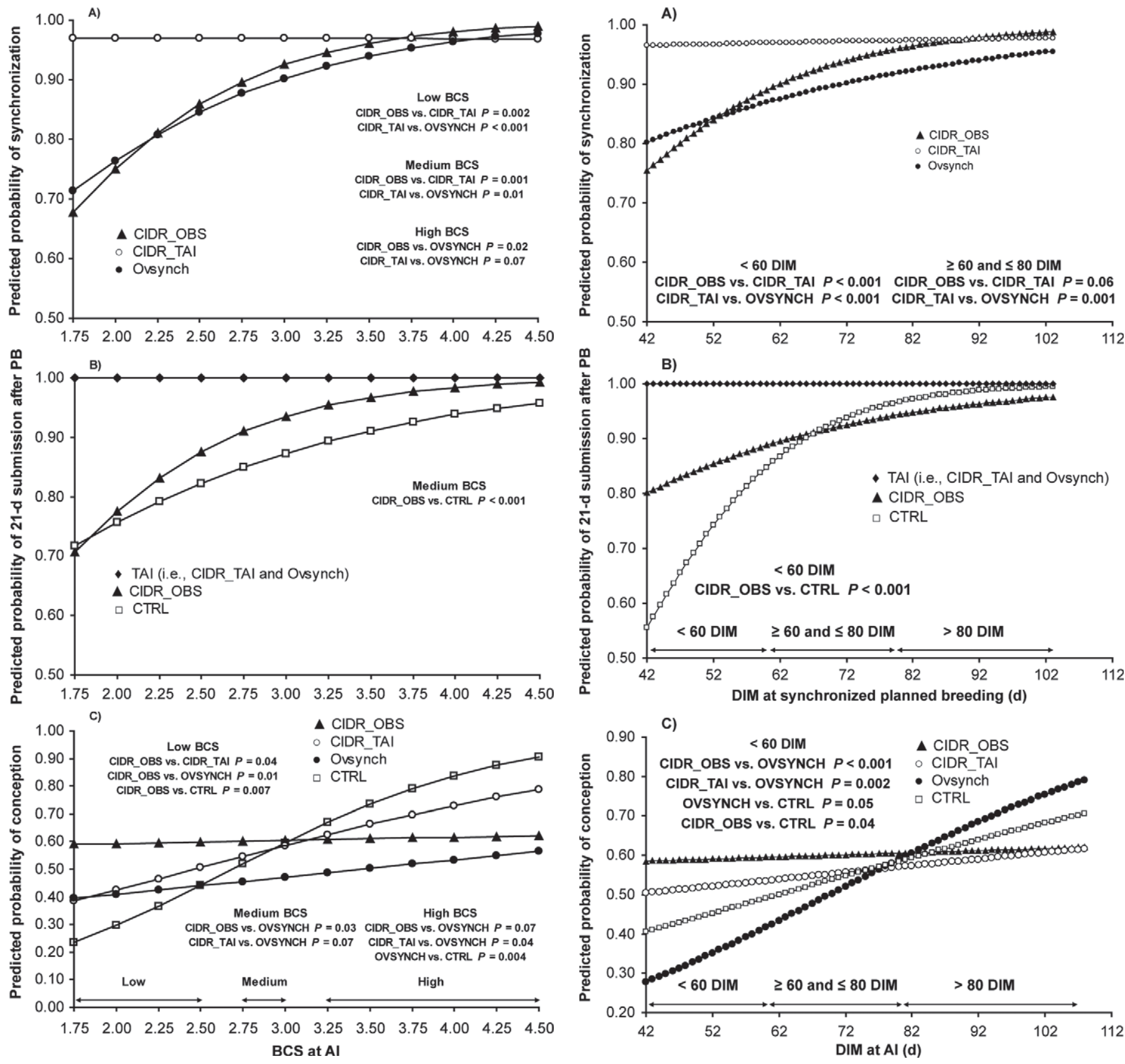

Figure 3. The association between BCS at AI and (A) synchronization rate, (B) 21-d submission rate after planned breeding (PB), and (C) conception rate at first service for different synchronization treatments; BCS at AI was included in the statistical model as a continuous variable. $\mathrm{CIDR}=$ controlled internal drug release; $\mathrm{OBS}=$ observed estrus; $\mathrm{TAI}=$ timed $\mathrm{AI} ; \mathrm{CTRL}=$ control.

\section{4\% FCM Yield on the Day of Al}

The interaction between synchronization treatment and $4 \% \mathrm{FCM}$ at AI was not significant for synchronization rate, 21-d submission rate after $\mathrm{PB}$, or conception rate at first service $(P=0.6, P=0.4, P=0.3$, respectively; Figure 6). Cows with high $4 \%$ FCM at AI

Figure 4. The association between DIM at the synchronized planned breeding (PB)/AI and (A) synchronization rate, (B) 21-d submission rate after $\mathrm{PB}$, and $(\mathrm{C})$ conception rate at first service for different synchronization treatments; DIM at synchronized PB/DIM at $\mathrm{AI}$ was included in the statistical model as a continuous variable. $\mathrm{CIDR}=$ controlled internal drug release; $\mathrm{OBS}=$ observed estrus; TAI $=$ timed $\mathrm{AI}$; CTRL $=$ control.

treated with CIDR-based protocols (i.e., CIDR_OBS and CIDR_TAI) had increased likelihood of conception at first service compared with animals treated with non-CIDR-based protocols (i.e., Ovsynch and CTRL), both in animals with $(\mathrm{OR}=2.02, P=0.03)$ and without $(\mathrm{OR}=2.94, P=0.01)$ a $\mathrm{CL}$ present at the onset 
A)

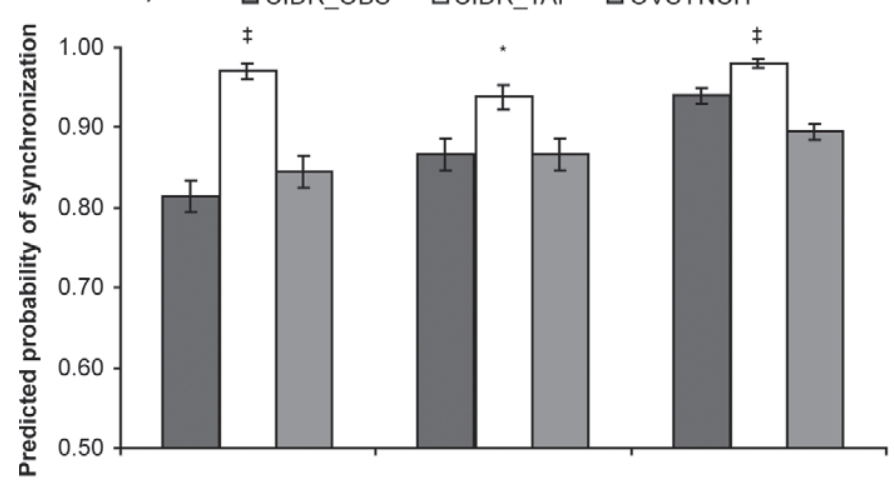

B)

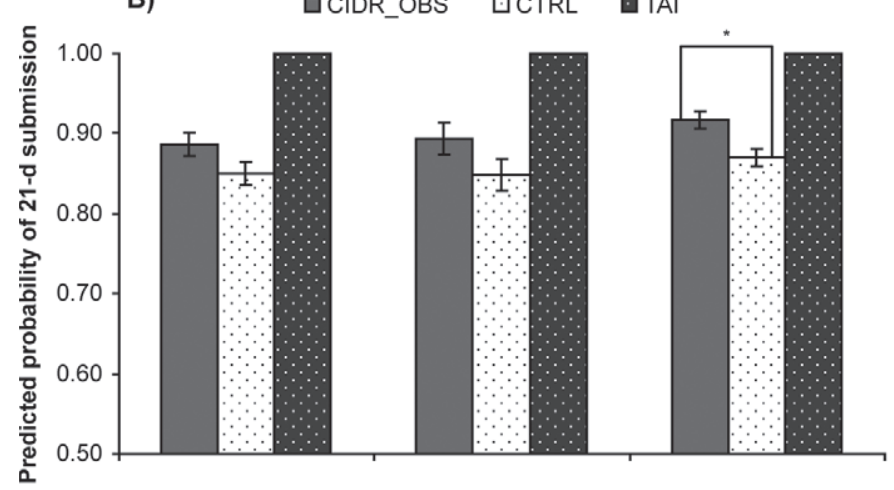

C) $\square$ CIDR_OBS aCIDR_TAI $\square O V S Y N C H$ DCTRL

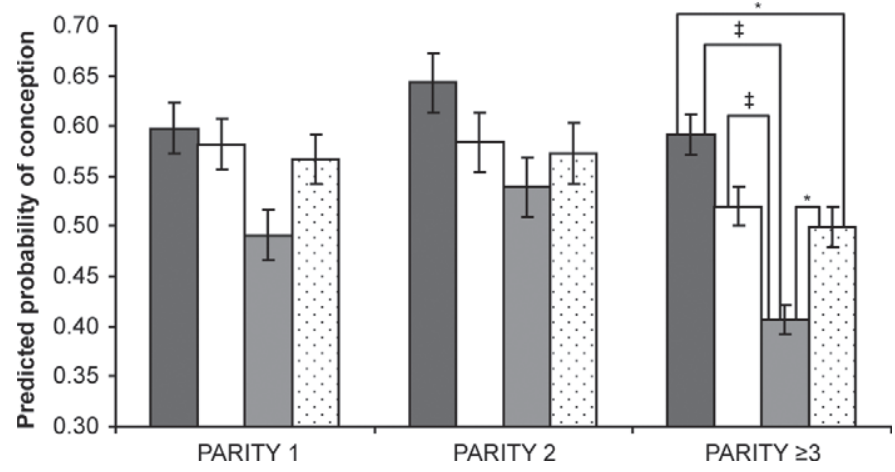

Figure 5. The association between parity and (A) synchronization rate, (B) 21-d submission rate after planned breeding, and (C) conception rate at first service for different synchronization treatments. $\ddagger$ Treatments differ within a particular parity $(P<0.05)$; *treatments tend to differ within a particular parity $(P \leq 0.10)$. CIDR $=$ controlled internal drug release; OBS $=$ observed estrus; TAI $=$ timed AI; CTRL $=$ control.

of synchronization. Preplanned contrasts used to compare treatment effects within $4 \% \mathrm{FCM}$ at AI category indicated greater synchronization rates for CIDR_TAI compared with CIDR_OBS and Ovsynch animals in the low $(+11.0$ and +7.0 percentage units, respectively), medium-low $(+5.0$ and +9.0 percentage units, respectively), and high $(+9.0$ and +13.0 percentage units, respectively) 4\% FCM at AI categories. In addition, preplanned contrasts used to compare treatment effects within $4 \% \mathrm{FCM}$ at AI category indicated greater conception rates for CIDR_OBS and CIDR_TAI animals in the high $4 \% \mathrm{FCM}$ at $\mathrm{AI}$ category when compared with Ovsynch $(+28.0$ and +25.0 percentage units, respectively) and CTRL (+17.0 and +14.0 percentage units, respectively).

\section{Circulating Progesterone Concentrations on Day 11 after Al}

One incidence of late embryo mortality after first service in an animal treated with CIDR_OBS was identified as an outlier for circulating concentrations of P4 on d 11 after AI in cows that underwent late embryo loss. This cow was subsequently removed from the statistical analysis relating circulating $\mathrm{P} 4$ to late embryo loss. The interaction between synchronization treatment and $\mathrm{P} 4$ on d 11 after AI was not significant for conception rate at first service or late embryo loss after first service $(P=0.9$ and $P=0.11$, respectively; Figure 7$)$. Concentration of $\mathrm{P} 4$ on d 11 after AI had no effect $(P=$ $0.7)$ on late embryo loss after first service. Preplanned contrasts used to compare treatment effects within P4 category on d 11 after AI indicated a 19.0 percentage units greater conception rate for CIDR_OBS animals in the low $\mathrm{P} 4$ category compared with animals treated with Ovsynch. In addition, late embryo loss rates after first service were lower for CIDR_OBS and CIDR_TAI (both -12.0 percentage units) animals in the mediumlow P4 category compared with Ovsynch.

\section{DISCUSSION}

This study identified factors associated with fertility outcomes in seasonal-calving lactating dairy cows treated with protocols to synchronize estrus and ovulation. Presence of a CL at protocol initiation, greater DIM at the onset of synchronization, and greater BCS at the time of AI were associated with increased likelihood of synchronization, submission for AI, conception at first service, and pregnancy at first service (Table 1). Use of a CIDR-based ovulation synchronization protocol (i.e., CIDR_TAI) increased synchronization rates in anovular cows (Figure 2). Absence of a CL at protocol initiation (Figure 2), low BCS (Figure 3 ), and <60 DIM (Figure 4) reduced the likelihood of conception for animals treated with Ovsynch, suggesting that Ovsynch is not an appropriate treatment for use on cows in these categories. For anovular cows, insemination based on observed estrus increased the likelihood of conception at first service compared with TAI (Figure 2). An increased likelihood of conception was observed for higher producing animals treated with CIDR-based protocols (Figure 6). It should be noted 


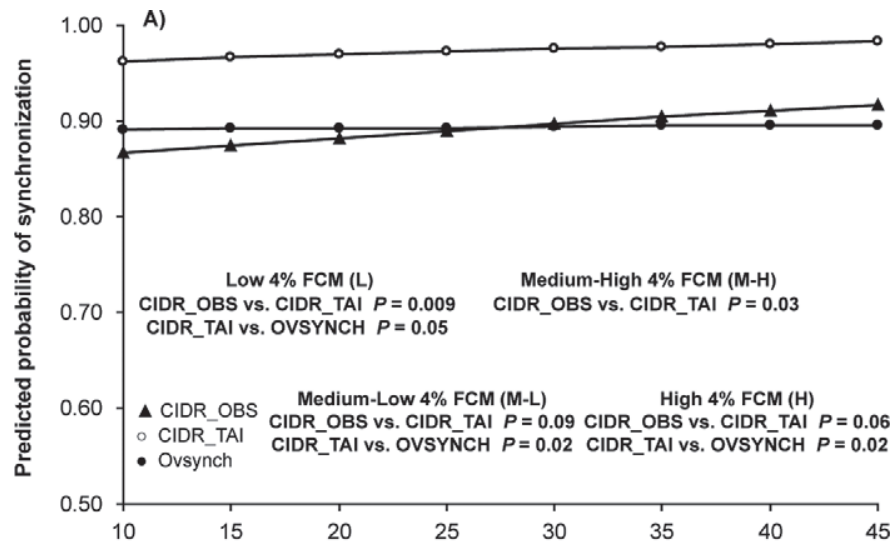

B)

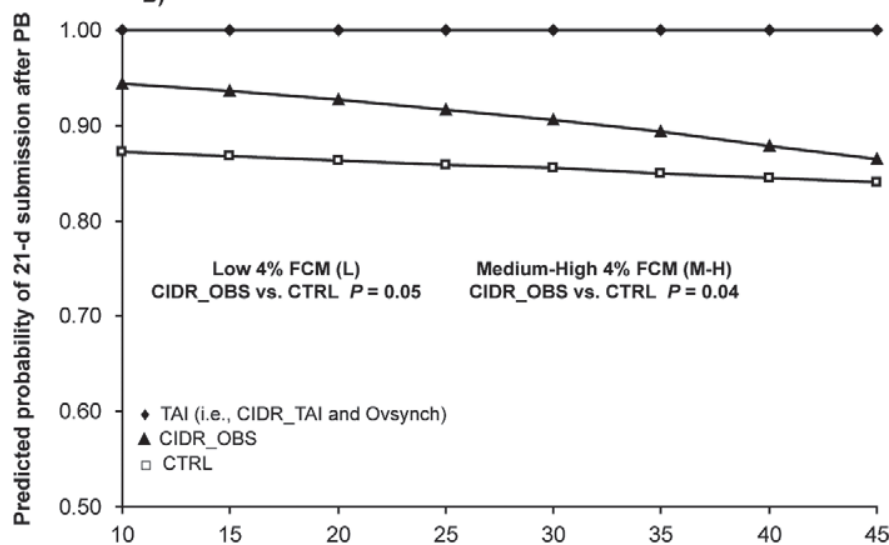

C)

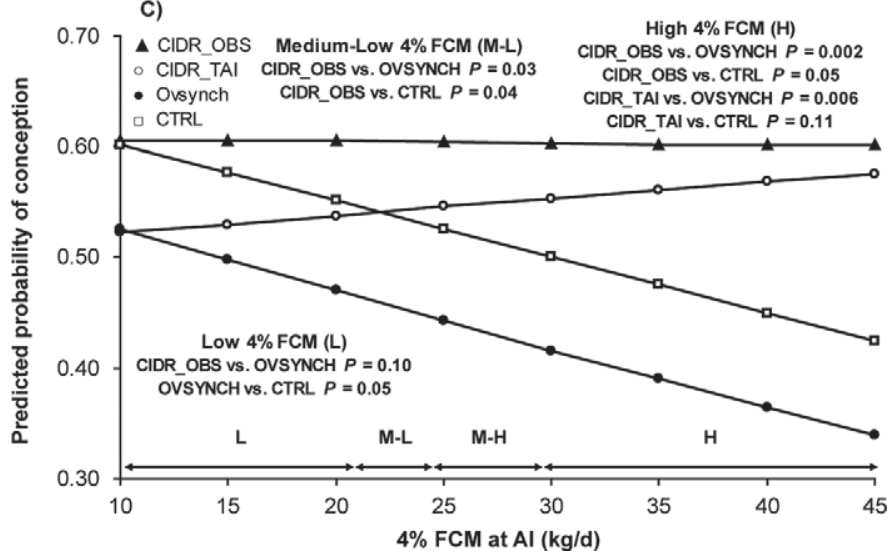

Figure 6. The association between $4 \% \mathrm{FCM}$ at AI and (A) synchronization rate, (B) 21-d submission rate after planned breeding $(\mathrm{PB})$, and $(\mathrm{C})$ conception rate at first service for different synchronization treatments; $4 \%$ FCM at AI was included in the statistical model as a continuous variable. CIDR $=$ controlled internal drug release; $\mathrm{OBS}=$ observed estrus; $\mathrm{TAI}=$ timed $\mathrm{AI} ; \mathrm{CTRL}=$ control.

that the graphical comparisons of interactions between synchronization treatment and explanatory variables (e.g., BCS or DIM) are most accurate in the regions of the data set containing most of the animal records. The values in the extremes (e.g., very high or very low BCS) are likely to be less reliable as a result of (1) the small
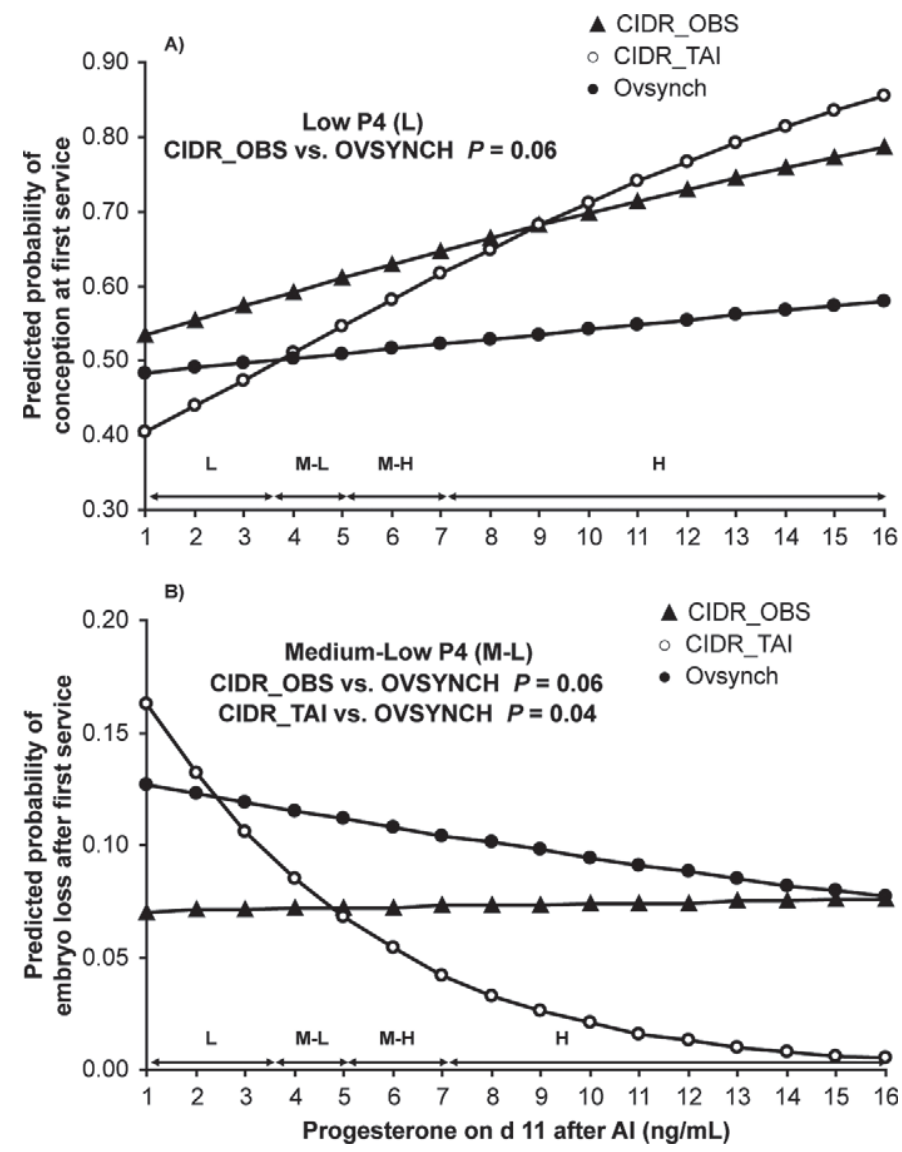

Figure 7. The association between progesterone (P4) on d 11 after AI and a) conception rate at first service and b) late embryo loss after first service for different synchronization treatments. Progesterone on d 11 after AI was included in the statistical model as a continuous variable. $\mathrm{CIDR}=$ controlled internal drug release; $\mathrm{OBS}=$ observed estrus; $\mathrm{TAI}=$ timed $\mathrm{AI}$.

number of animals in these regions of the data set; and (2) the greater influence of individual animals on the shape of the response curve.

Animals treated with CIDR_TAI had increased likelihood of synchronization compared with CIDR_OBS and Ovsynch, in both animals with and without a LF at the onset of synchronization (Figure 2). In agreement with these findings, other recent studies have also reported greater synchronization rates when $\mathrm{P} 4$ was supplemented during ovulation synchronization protocols (Stevenson et al., 2006, 2008; Chebel et al., 2010). $\mathrm{Xu}$ et al. (1997) synchronized lactating dairy cows using 2 injections of $\mathrm{PGF}_{2 \alpha}$ administered $13 \mathrm{~d}$ apart and supplemented or not with a CIDR for $5 \mathrm{~d}$ before the second $\mathrm{PGF}_{2 \alpha}$ to increase circulating P4 before AI. An improvement in estrous response after the second $\mathrm{PGF}_{2 \alpha}$ and in conception rate to first insemination in cows inseminated after detected estrus was observed in response to $\mathrm{P} 4$ supplementation ( $\mathrm{Xu}$ et al., 1997). In the present study, the CIDR device was inserted for 8 
$\mathrm{d}$ and removed $1 \mathrm{~d}$ after the $\mathrm{PGF}_{2 \alpha}$ injection, based on previous reports of improved precision in the onset of estrus when CIDR inserts were removed after an 8-d treatment period ( $\mathrm{Xu}$ and Burton, 2000).

In cows with no CL at the onset of synchronization, synchronization rates were greater in animals treated with CIDR_TAI compared with Ovsynch (Figure 2), possibly a result of reduced incidence of premature luteal regression (Bello et al., 2006). Conversely, greater synchronization rates in cows treated with CIDR_TAI compared with CIDR_OBS likely arose from forced ovulation following GnRH2 (Herlihy et al., 2012).

In the present study, the incidence of anovulation was greater among primiparous animals compared with multiparous animals, corroborating previous studies (Moreira et al., 2001; Gümen et al., 2003). Exposure to P4 during synchronization followed by ovulation induction using GnRH2 may have improved synchronization rates in primiparous animals treated with CIDR_TAI. In addition, third and greater parity animals treated with CIDR_TAI and CIDR_OBS in the present study had increased likelihood of synchronization compared with those treated with Ovsynch (Figure 5).

Greater submission rates were achieved when cows had a CL present at the onset of synchronization and had greater DIM (Table 1). Cows that have resumed cyclicity before the first postpartum AI have greater fertility than anovular cows, primarily due to $\mathrm{P} 4$ priming and improved uterine health (Santos et al., 2009; Thatcher et al., 2010). Early re-establishment of luteal activity postpartum is a prerequisite to maximize 3 -wk submission rate (Macmillan, 2002) and to maintain a compact calving pattern (Morton, 2010). Cows with an extended postpartum anovulatory interval are a major cause of suboptimal reproductive performance in seasonal calving herds (Rhodes et al., 2003). The lowest submission rates were achieved with animals $<60$ DIM at AI (Table 1). For these animals, use of TAI protocols and CIDR_OBS resulted in greater submission rates compared with untreated controls (Figure 4). Low-BCS animals had a reduced likelihood of submission in the first $21 \mathrm{~d}$ after PB compared with medium- and highBCS animals (Table 1). These findings are in agreement with Buckley et al. (2003), who reported that lower average BCS between 60 and 100 DIM was associated with a lower probability of submission for AI in the first 3 wk of the breeding season.

In agreement with the findings of McDougall (2010a), greater conception rates were achieved when cows had a CL present at the onset of synchronization (Table 1). Absence of a CL reduced the likelihood of conception for animals treated with Ovsynch $(\mathrm{OR}=0.54, P=$ 0.008; Figure 2). Acceptable fertility performance has previously been reported when Ovsynch was used with ovular cows, but not with anovular cows (Moreira et al., 2001; Gümen et al., 2003; Stevenson et al., 2006). Absence of a CL did not reduce the likelihood of conception for animals treated with CIDR-based protocols, suggesting that fertility was not compromised in anovular cows when P4 was supplemented (Figure 2). Animals without a CL at the onset of synchronization treated with CIDR_TAI had an increased likelihood of conception compared with animals treated with Ovsynch $(1.94, P=0.008)$, highlighting the beneficial role of supplemental P4 in anovular cows bred with TAI (Figure 2). McDougall (2010b) reported that treatment of anestrous cows $(+/-\mathrm{CL})$ was more cost-effective than no treatment, with Ovsynch and P4 (similar to CIDR_TAI) being more cost-effective than Ovsynch.

In the present study, low-BCS animals treated with CIDR_OBS had an increased likelihood of conception at first service compared with low-BCS animals treated with CIDR_TAI, Ovsynch, or CTRL (Figure $3)$. In agreement with the findings of the present study, Moreira et al. (2000) and Galvão and Santos (2010) reported that low BCS negatively influenced pregnancy rates of cows submitted to Ovsynch. Burke et al. (1996) reported greater conception rates in cows with greater BCS at the onset of Ovsynch. Cows in the low BCS category would have increased likelihood of delayed resumption of cyclicity (Chebel et al., 2006; Bamber et al., 2009; Santos et al., 2009). McDougall et al. (1995) described the pattern of follicular development in pasture-fed dairy herds and reported that the interval from calving to the first postpartum ovulation averaged 43.4 d (range 13 to 93 d). Burke and Roche (2007) demonstrated that the postpartum anovulatory interval in multiparous grazing dairy cows was not affected by postpartum intake. Hormonal treatment involving the use of Ovsynch supplemented with P4 is currently the most effective strategy for treating anestrous dairy cows in New Zealand (McDougall, 2010a). Greater DIM was associated with more favorable conception rate outcomes (Table 1). This is in agreement with earlier findings that demonstrated lower conception rates when Ovsynch was initiated at 50 to $75 \mathrm{~d}$ postpartum compared with >76 DIM (Pursley et al., 1998).

Milk production (i.e., 4\% FCM at AI) had no effect on the likelihood of synchronization, submission for AI, or conception at first service, supporting recent studies that suggest a lack of association between milk production and reproduction (Table 1; Morton, 2001; Patton et al., 2007). Preplanned contrasts used to compare treatment effects within different milk yield categories revealed increased likelihood of conception for higher producing animals treated with CIDR-based protocols (Figure 6). This observation was true for animals that did and did not have a CL present at the onset of synchronization. 
Animals with low $\mathrm{P} 4(<3.50 \mathrm{ng} / \mathrm{mL})$ on d 11 after AI had reduced likelihood of conceiving at first service (Table 1). Systemic concentrations of $\mathrm{P} 4$ and the rate of P4 increase during the early luteal phase of the cycle after AI affect embryo survival (Morris and Diskin, 2008) through P4-induced changes in the uterine environment that are responsible for advancements in conceptus elongation (Clemente et al., 2009; Forde et al., 2011).

Minor differences between treatments in synchronization rate were observed for animals that had a CL present at the onset of synchronization (Figure 2). In contrast, absence of a CL reduced the likelihood of synchronization for animals treated with CIDR_OBS and Ovsynch compared with CIDR_TAI (Figure 2). Animals with low BCS (Figure 3) and animals $<60$ DIM (Figure 4) treated with CIDR_TAI had increased likelihood of synchronization compared with similar animals treated with CIDR_OBS. Animals with low BCS treated with CIDR_OBS, however, had increased likelihood of conception compared with similar animals treated with CIDR_TAI, Ovsynch and CTRL (Figure $3)$. This is in agreement with a large-scale study that used Ovsynch on 3,559 cycling and noncycling cows in 14 seasonal-calving dairy herds in Australia and New Zealand (Shephard, 2005). That study reported that the odds of TAI pregnancy increased significantly for cows that were calved more than $40 \mathrm{~d}$ at the time of AI, in greater BCS, and cycling (Shephard, 2005).

The pregnancy rate following synchronization is a product of the submission rate and the conception rate achieved. The pregnancy rates for low-BCS animals treated with CIDR_OBS $(0.83 \times 0.61=0.51)$ and CIDR_TAI $(1.00 \times 0.46=0.46)$ were similar, and both were greater than those for Ovsynch $(1.00 \times 0.43$ $=0.43)$ and CTRL $(0.84 \times 0.40=0.34)$. Pregnancy rates for animals <60 DIM (CIDR_OBS: $0.86 \times 0.60$ $=0.52 ;$ CIDR_TAI: $1.00 \times 0.51=0.51 ;$ Ovsynch: 1.00 $\times 0.33=0.33$; CTRL: $0.71 \times 0.45=0.32)$ and cows without a CL present at the onset of synchronization [CIDR_OBS: $0.88 \times 0.58=0.51$; CIDR_TAI: 1.00 $\times 0.52=0.52$; Ovsynch: $1.00 \times 0.36=0.36$; CTRL: $0.82 \times 0.50=0.41]$ were similar for CIDR_OBS and CIDR_TAI, both of which were greater than Ovsynch and CTRL. These results indicate that greater synchronization rates and $100 \%$ submission rate achieved with CIDR_TAI in animals categorized as low BCS, anovulatory, or $<60$ DIM were offset by greater conception rates in animals treated with CIDR_OBS.

\section{CONCLUSIONS}

Presence of a CL, greater BCS, and greater DIM at the onset of synchronization were associated with increased likelihood of synchronization, submission for AI, con- ception at first service, and pregnancy at first service in cows treated with protocols to synchronize estrus and ovulation. Our findings indicate that CIDR-based protocols should be targeted at animals categorized at the time of protocol initiation as low BCS, anovulatory, or $<60$ DIM. The decision to use CIDR_OBS or CIDR_TAI in cows within these categories should be made based on expected heat detection efficiency on the farm versus the management efficiency afforded by using TAI. Strategies to promote cyclicity, greater $\mathrm{BCS}$, and greater circulating P4 during synchronization should lead to improved fertility outcomes in lactating dairy cows treated with protocols to synchronize estrus and ovulation in seasonal-calving, pasture-based dairy production systems.

\section{ACKNOWLEDGMENTS}

We thank the participating herd owners and their staff for their help and cooperation during the trial. Technical support was provided by Tommy Condon, Billy Curtin, Jonathon Kenneally (all of Teagasc, Animal and Grassland Research and Innovation Centre, Moorepark, Fermoy, Co. Cork, Ireland), Assumpta Glynn (Teagasc, Animal and Grassland Research and Innovation Centre, Mellows Campus, Athenry, Co. Galway, Ireland) and professional work experience students from University College Dublin. We acknowledge the Irish Cattle Breeding Federation (Bandon, Co. Cork, Ireland) for test-day milk records supplied. Pfizer Ireland (Dublin, Ireland) donated the CIDR inserts used in this trial. This study was funded by the National Development Plan and the Dairy Levy Trust Fund.

\section{REFERENCES}

Bamber, R. L., G. E. Shook, M. C. Wiltbank, J. E. Santos, and P. M. Fricke. 2009. Genetic parameters for anovulation and pregnancy loss in dairy cattle. J. Dairy Sci. 92:5739-5753.

Bello, N. M., J. P. Steibel, and J. R. Pursley. 2006. Optimizing ovulation to first GnRH improved outcomes to each hormonal injection of Ovsynch in lactating dairy cows. J. Dairy Sci. 89:3413-3424.

Buckley, F., K. O'Sullivan, J. F. Mee, R. D. Evans, and P. Dillon. 2003. Relationships among milk yield, body condition, cow weight, and reproduction in spring-calved Holstein-Friesians. J. Dairy Sci. $86: 2308-2319$.

Burke, C. R., and J. R. Roche. 2007. Effects of pasture feeding during the periparturient period on postpartum anovulation in grazed dairy cows. J. Dairy Sci. 90:4304-4312.

Burke, J. M., R. L. sal Sota, C. A. de la Risco, C. R. Staples, E. J. Schmitt, and W. W. Thatcher. 1996. Evaluation of timed insemination using a gonadotropin-releasing hormone agonist in lactating dairy cows. J. Dairy Sci. 79:1385-1393.

Butler, W. R., and R. D. Smith. 1989. Interrelationships between energy balance and postpartum reproductive function in dairy cattle. J. Dairy Sci. 72:767-783.

Chebel, R. C., M. J. Al-Hassan, P. M. Fricke, J. E. Santos, J. R. Lima, C. A. Martel, J. S. Stevenson, R. Garcia, and R. L. Ax. 2010. Supplementation of progesterone via controlled internal drug release inserts during ovulation synchronization protocols in lactating dairy cows. J. Dairy Sci. 93:922-931. 
Chebel, R. C., J. E. Santos, R. L. Cerri, H. M. Rutigliano, and R. G. Bruno. 2006. Reproduction in dairy cows following progesterone insert presynchronization and resynchronization protocols. J. Dairy Sci. 89:4205-4219.

Clemente, M., J. de La Fuente, T. Fair, A. Al Naib, A. Gutierrez-Adan, J. F. Roche, D. Rizos, and P. Lonergan. 2009. Progesterone and conceptus elongation in cattle: A direct effect on the embryo or an indirect effect via the endometrium? Reproduction 138:507-517.

Dillon, P., S. Crosse, G. Stakelum, and F. Flynn. 1995. The effect of calving date and stocking rate on the performance of springcalving dairy cows. Grass Forage Sci. 50:286-299.

Edmonson, A. J., I. J. Lean, L. D. Weaver, T. Farver, and G. Webster. 1989. A body condition scoring chart for Holstein dairy cows. J. Dairy Sci. 72:68-78.

Forde, N., M. E. Beltman, G. B. Duffy, P. Duffy, J. P. Mehta, P. O'Gaora, J. F. Roche, P. Lonergan, and M. A. Crowe. 2011. Changes in the endometrial transcriptome during the bovine estrous cycle: Effect of low circulating progesterone and consequences for conceptus elongation. Biol. Reprod. 84:266-278.

Gaines, W. L., and F. A. Davidson. 1923. Relation between percentage fat content and yield of milk. Pages 207-232 in Agric. Exp. Stat. Bull. Vol. 245. University of Illinois Agricultural Experiment Station, Champaign.

Galvão, K. N., and J. E. Santos. 2010. Factors affecting synchronization and conception rate after the Ovsynch protocol in lactating Holstein cows. Reprod. Domest. Anim. 45:439-446.

Gümen, A., J. N. Guenther, and M. C. Wiltbank. 2003. Follicular size and response to Ovsynch versus detection of estrus in anovular and ovular lactating dairy cows. J. Dairy Sci. 86:3184-3194.

Herlihy, M. M., D. P. Berry, M. A. Crowe, M. G. Diskin, and S. T. Butler. 2011. Evaluation of protocols to synchronize estrus and ovulation in seasonal calving pasture-based dairy production systems. J. Dairy Sci. 94:4488-4501.

Herlihy, M. M., M. A. Crowe, M. G. Diskin, and S. T. Butler. 2012. Effects of synchronization treatments on ovarian follicular dynamics, corpus luteum growth, and circulating steroid hormone concentrations in lactating dairy cows. J. Dairy Sci. 95:743-754.

Lopez, H., L. D. Satter, and M. C. Wiltbank. 2004. Relationship between level of milk production and estrous behavior of lactating dairy cows. Anim. Reprod. Sci. 81:209-223.

Macmillan, K. L. 2002. Advances in bovine theriogenology in New Zealand. 2. Breeding management and technologies for improved reproduction. N. Z. Vet. J. 50:74-80.

Macmillan, K. L. 2010. Recent advances in the synchronization of estrus and ovulation in dairy cows. J. Reprod. Dev. 56(Suppl.):S42-S47.

Macmillan, K. L., and A. J. Peterson. 1993. A new intravaginal progesterone releasing device for cattle (CIDR-B) for oestrous synchronisation, increasing pregnancy rates and the treatment of postpartum anoestrus. Anim. Reprod. Sci. 33:1-25.

McDougall, S. 2006. Reproduction performance and management of dairy cattle. J. Reprod. Dev. 52:185-194.

McDougall, S. 2010a. Effects of treatment of anestrous dairy cows with gonadotropin-releasing hormone, prostaglandin, and progesterone. J. Dairy Sci. 93:1944-1959.

McDougall, S. 2010b. Comparison of diagnostic approaches, and a cost-benefit analysis of different diagnostic approaches and treatments of anoestrous dairy cows. N. Z. Vet. J. 58:81-89.

McDougall, S., C. R. Burke, K. L. MacMillan, and N. B. Williamson. 1995. Patterns of follicular development during periods of anovulation in pasture-fed dairy cows after calving. Res. Vet. Sci. $58: 212-216$.

Mee, J. F., F. Buckley, D. Ryan, and P. Dillon. 2009. Pre-breeding ovaro-uterine ultrasonography and its relationship with first service pregnancy rate in seasonal-calving dairy herds. Reprod. Domest. Anim. 44:331-337.

Moreira, F., C. Orlandi, C. A. Risco, R. Mattos, F. Lopes, and W. W. Thatcher. 2001. Effects of presynchronization and bovine somatotropin on pregnancy rates to a timed artificial insemination protocol in lactating dairy cows. J. Dairy Sci. 84:1646-1659.

Moreira, F., C. Risco, M. F. A. Pires, J. D. Ambrose, M. Drost, M. DeLorenzo, and W. W. Thatcher. 2000. Effect of body condition on reproductive efficiency of lactating dairy cows receiving a timed insemination. Theriogenology 53:1305-1319.

Morris, D., and M. Diskin. 2008. Effect of progesterone on embryo survival. Animal 2:1112-1119.

Morton, J. M. 2001. High genetic merit and high-producing dairy cows in commercial Australian herds don't have substantially worse reproductive performance. Anim. Sci. 26:305-311.

Morton, J. M. 2010. Interrelationships between herd-level reproductive performance measures based on intervals from initiation of the breeding program in year-round and seasonal calving dairy herds. J. Dairy Sci. 93:901-910.

Nebel, R. L., W. L. Walker, M. L. McGilliard, C. H. Allen, and G. S. Heckman. 1994. Timing of artificial insemination of dairy cows: Fixed-time once daily versus morning and afternoon. J. Dairy Sci. $77: 3185-3191$.

Patton, J., D. A. Kenny, S. McNamara, J. F. Mee, F. P. O’Mara, M. G. Diskin, and J. J. Murphy. 2007. Relationships among milk production, energy balance, plasma analytes, and reproduction in Holstein-Friesian cows. J. Dairy Sci. 90:649-658.

Pursley, J. R., R. W. Silcox, and M. C. Wiltbank. 1998. Effect of time of artificial insemination on pregnancy rates, calving rates, pregnancy loss, and gender ratio after synchronization of ovulation in lactating dairy cows. J. Dairy Sci. 81:2139-2144.

Rhodes, F. M., S. McDougall, C. R. Burke, G. A. Verkerk, and K. L. Macmillan. 2003. Invited review: Treatment of cows with an extended postpartum anestrous interval. J. Dairy Sci. 86:1876-1894.

Roche, J. R., N. C. Friggens, J. K. Kay, M. W. Fisher, K. J. Stafford and D. P. Berry. 2009. Invited review: Body condition score and its association with dairy cow productivity, health, and welfare. J. Dairy Sci. 92:5769-5801.

Santos, J. E., H. M. Rutigliano, and M. F. Sa Filho. 2009. Risk factors for resumption of postpartum estrous cycles and embryonic survival in lactating dairy cows. Anim. Reprod. Sci. 110:207-221.

SAS Institute. 2006. SAS User's Guide: Statistics. SAS Institute Inc. Cary, NC.

Shephard, R. W. 2005. A comparison of performance of the Ovsynch treatment program between cycling and non-cycling cows within seasonally-calving dairy herds. Aust. Vet. J. 83:751-757.

Stevenson, J. S., J. R. Pursley, H. A. Garverick, P. M. Fricke, D. J. Kesler, J. S. Ottobre, and M. C. Wiltbank. 2006. Treatment of cycling and noncycling lactating dairy cows with progesterone during Ovsynch. J. Dairy Sci. 89:2567-2578.

Stevenson, J. S., D. E. Tenhouse, R. L. Krisher, G. C. Lamb, J. E. Larson, C. R. Dahlen, J. R. Pursley, N. M. Bello, P. M. Fricke, M. C. Wiltbank, D. J. Brusveen, M. Burkhart, R. S. Youngquist, and H. A. Garverick. 2008. Detection of anovulation by heatmount detectors and transrectal ultrasonography before treatment with progesterone in a timed insemination protocol. J. Dairy Sci. 91:2901-2915.

Tenhagen, B. A., M. Drillich, and W. Heuwieser. 2001. Analysis of cow factors influencing conception rates after two timed breeding protocols. Theriogenology 56:831-838.

Tenhagen, B.-A., R. Surholt, M. Wittke, C. Vogel, M. Drillich, and W. Heuwieser. 2004. Use of Ovsynch in dairy herds - Differences between primiparous and multiparous cows. Anim. Reprod. Sci. $81: 1-11$.

Tenhagen, B.-A., C. Vogel, M. Drillich, G. Thiele, and W. Heuwieser. 2003. Influence of stage of lactation and milk production on conception rates after timed artificial insemination following Ovsynch. Theriogenology 60:1527-1537.

Thatcher, W., J. Santos, F. Silvestre, I. Kim, and C. Staples. 2010. Perspective on physiological/endocrine and nutritional factors influencing fertility in post-partum dairy cows. Reprod. Domest. Anim. 45:2-14.

Xu, Z. Z., and L. J. Burton. 2000. Estrus synchronization of lactating dairy cows with $\mathrm{GnRH}$, progesterone, and prostaglandin $\mathrm{F}_{2 \alpha}$. J. Dairy Sci. 83:471-476.

Xu, Z. Z., L. J. Burton, and K. L. Macmillan. 1997. Reproductive performance of lactating dairy cows following estrus synchronization regimens with $\mathrm{PGF}_{2 \alpha}$ and progesterone. Theriogenology 47:687-701. 